\title{
The Effect of Visual Merchandising, Store Atmosphere, and Emotional Response on Impulsive Purchases
}

Febriansyah ${ }^{*}$,

Calvin Sukendra ${ }^{2}$,

${ }^{1}$ Management, Economic Faculty, STIE GICI Business School , Depok, West Java, Indonesia

2 Management, Economic Faculty, Institut Teknologi dan Bisnis Kalbis Jakarta,Jakarta, Indonesia

\begin{tabular}{|c|c|}
\hline ARTICLE INFO & ABSTRACT \\
\hline $\begin{array}{l}\text { ISSN: 2723-1097 } \\
\text { Keywords: } \\
\text { visual merchandising; } \\
\text { store atmosphere; } \\
\text { emotional response; } \\
\text { impulsive buying. }\end{array}$ & $\begin{array}{l}\text { This study aims to determine and analyze the effect of visual merchandising and } \\
\text { store atmosphere on emotional response and its impact on impulsive buying. The } \\
\text { population uses non-probability techniques using judgmental sampling. The } \\
\text { sample consisted of } 130 \text { consumers of Mimi Kado. The data analysis technique used } \\
\text { is multiple linear regression and the } T \text { test. The results showed that visual } \\
\text { merchandising has a positive and significant effect on the emotional response of } \\
\text { Mimi Kado visitors with a beta coefficient value of } 0.219 \text { and } t \text { value }(2,387)>t \\
\text { table (1,978), shop atmosphere. has a positive and significant effect on the emotional } \\
\text { response of Mimi Kado visitors with a beta coefficient value of } 0.431 \text { and a value of } \\
\text { t count (4.699)> t table (1.978), emotional response has a positive and significant } \\
\text { effect on impulsive buying of Mimi Kado visitors with a beta coefficient value of } \\
\text { 0.450 and a value of t arithmetic (5.703)> t table (1.978). So it can be suggested } \\
\text { the following: take more samples in order to represent perceptions more broadly, } \\
\text { take data during peak season, understand priorities in doing research, use the same } \\
\text { model but with different research objects, pay attention to linking an indicator with } \\
\text { strategic theory, Doing with a planned time and with attention to the respondents } \\
\text { only those who have visited and made transactions. }\end{array}$ \\
\hline
\end{tabular}

\section{Pendahuluan}

Dalam perkembangan globalisasi, Ditengah perkembangan zaman seperti ini, diperlukan bisnis yang mampu memberikan hasil timbal balik yang memuaskan serta dapat menjadi salah satu alat investasi bagi para investor. Ada banyak jenis bisnis yang terdapat di Indonesia, salah satunya adalah bisnis ritel. Bisnis ritel menurut Utami (2010:5) adalah semua kegiatan yang terlibat dalam penjualan barang atau jasa secara langsung kepada konsumen akhir untuk penggunaan pribadi dan bukan penggunaan bisnis. Hingga saat ini, bisnis ritel sekarang pun mengalami penurunan. Pasalnya, adanya beberapa faktor yang mempengaruhi penurunan bisnis ritel ini, bahkan ada beberapa ritel yang sampai menutup gerai ritelnya dan sampai hengkang dari dunia ritel Indonesia. Faktor yang pertama adalah karena adanya belanja online. Adanya peningkatan penggunaan dari segi teknologi pun melahirkan jenis usaha

Journal of Business and Management Review Vol. 1 No. 42020 Page 269-280

DOI: $10.47153 /$ jbmr14.432020

*Corresponding Author

Email address: febriansyahali9@gmail.com 
baru, jual-beli secara onlne. Tren belanja online yang semakin gencar membuat penjualan fisik di dalam gedung peritel pun berkurang, ditambah adanya HarBolNas (Hari Belanja Online Nasional) yang dilaksanakan para e-commerce pun mendukung angka penurunan ini. Adapun penjualan nyata ritel selama triwulan 3 tahun terakhir sebagai berikut (data diambil dari laporan survey BI 2018) :

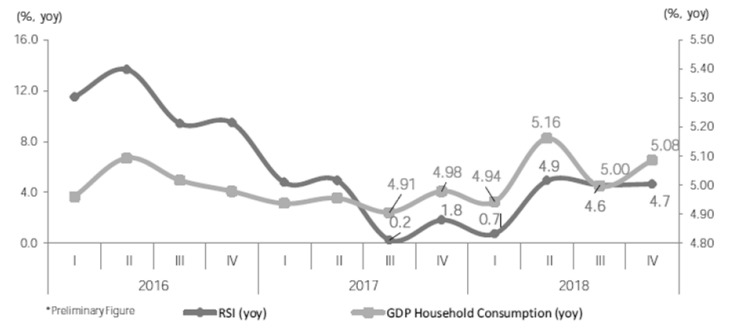

Gambar 1 Data penjualan ritel triwulan 3 tahun terakhir Sumber : Bi.go.id

Dari data tersebut, peritel melaporkan pembacaan penjualan tahunan yang lebih kuat pada kuartal keempat tahun 2018 yang meskipun mengalami penurunan dibandingkan dengan kondisi pada periode sebelumnya. Meningkat dari 4.6\% (yoy) pada kuartal ketiga 2018 dan dari 1.8\% (yoy) pada kuartal keempat 2017 menjadi 4.7\% (yoy) dalam tiga bulan hingga Desember 2018. Perkembangan tersebut konsisten dengan konsumsi rumah tangga terhadap PDB, yang meningkat dari $5.00 \%$ (yoy) pada kuartal ketiga 2018 dan dari 4.98\% (yoy) pada kuartal keempat kuartal 2017 menjadi $5.08 \%$ (yoy) pada kuartal akhir 2018. Data tersebut menunjukkan peningkatan namun masih di angka yang minimum. Adanya tren dari offline ke online dalam masalah belanja. Kurangnya adaptasi serta inovasi yang cepat membuat peritel pun cukup kebingungan dalam menghadapi perkembangan teknologi saat ini. Mochtar Riady, Founder Lippo Group dilansir dalam beritasatu.com (diakses pada tanggal 7 Maret 2019 pukul 10:25) mengatakan bahwa jika pengusaha sekarang ini tidak mengikuti perkembangan teknologi, maka akan mempengaruhi keberlangsungan bisnisnya. Bahkan, menurut katadata.co.id (diakses pada tanggal 7 Maret 2019 pukul 10:35).

Faktor kedua adalah dikarenakan pola belanja masyarakat yang sudah berubah. Dilihat dari grafik diatas, tingkat daya beli masyarakat itu sendiri pun masih berfluktuasi tiap triwulannya. Adanya juga pola belanja masyarakat yang berubah dikarenakan masyarakat lebih memilih untuk bebelanja secara online. Darmin Nasution, Menko Bidang Perekonomian dilansir dalam finance.detik.com (diakses pada tanggal 25 Juni 2019 pukul 1:40) mengatakan bahwa ditutupnya sejumlah ritel karena adanya peralihan model belanja. Kehadiran e-commerce menjadi salah satu perubahan pola belanja yang disebutkan. Kedua faktor ini lah yang membuat ritel 
mengalami penurunan dalam bidang bisnisnya. Peneliti pun melakukan survey kepada 5 toko ritel kecil di sekitaran daerah Jakarta Utara yang menjual barang barang khusus yaitu toko A, toko B, toko C, toko D, dan toko E. Adapun hasil yang di dapat adalah sebagai berikut:

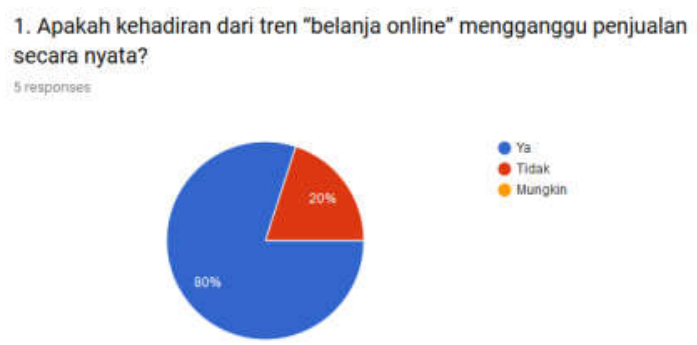

Gambar 2 Pra-Survey

Sumber : Olahan Peneliti, 2019

Dari ke-5 peritel yang di wawancara, 4 dari 5 peritel mengatakan bahwa kehadiran tren 'belanja online' cukup mengganggu penjualan tokonya secara nyata dan hanya satu peritel yang mengatakan kehadiran tren tersebut tidak mengganggu penjualan secara nyata. Itulah sebabnya, kehadiran tren tersebut mengganggu bukan hanya pada peritel besar, namun juga para peritel kecil yang menjual barang - barang khusus.

Meskipun ada banyak peritel yang mulai menyerah akan keadaan pasar yang semakin kuat, ada juga peritel yang masih percaya akan bisnisnya dan bahkan berekspansi untuk menambah gerainya yang baru salah satunya adalah Mimi Kado. Mimi Kado merupakan toko ritel yang khusus menjual peralatan pesta dan berbagai jenis kado. Mimi Kado pun merupakan salah satu speciality stores, yaitu toko yang berkonsentrasi pada sejumlah kategori barang dagangan komplementer dan memberikan tingkat layanan yang tinggi di toko yang relatif kecil. Dari hasil wawancara yang dilakukan peneliti kepada pemilik dari Mimi Kado, Octaverius Wiro, mengatakan bahwa persaingan di dalam dunia ritel speciality stores ini cukup dibilang ketat. Pasalnya, ada cukup banyak toko serupa disekitaran daerah Jakarta Utara. Ditambah lagi, toko sebelah toko Mimi Kado, Toko Setia Kawan yang berawal hanya menjual buku dan menerima jasa fotocopy, kini mulai mengambil pangsa pasar Mimi Kado untuk menjual barang-barang unik yang serupa dengan Mimi Kado. Pemilik toko mengatakan bahwa apakah yang dimiliki Mimi Kado, dari segi tampilan toko, barang dagang, serta kebaharuan produk dapat mempengaruhi konsumen sehingga dapat melakukan pembelian di dalam toko Mimi Kado itu sendiri sehingga dapat meningkatkan laba dari Mimi Kado dibanding dengan speciality stores di pasar ritel. 
Berdasarkan uraian latar belakang di atas, maka penulis menentukan judul "Pengaruh Barang Visual dan Atmosfer Toko Terhadap Respon Emosional Serta Dampaknya pada Pembelian Impulsif pada Mimi Kado Jakarta Utara.

\section{Metode Penelitian}

\section{A. Jenis Penelitian}

Penelitian ini menggunakan metode kuantitatif dengan menggunakan nonprobability sampling dengan teknk judgemental sampling, dimana penarikan sampel berdasarkan pertimbangan yang didasarkan kriteria-kriteria tertentu. Responden dalam penelitian ini adalah responden yang telah mengunjungi dan membeli produk Mimi Kado Jakarta Utara. Variabel yang diuji adalah visual merchandising dan atmosfer toko sebagai variabel independen, variabel respon emosional sebagai variabel intervening serta pembelian impulsif sebagai variabel dependen.

\section{B. Populasi dan Sampel}

Populasi dalam penelitian ini yaitu konsumen yang mengetahui, pernah mengunjungi dan melakukan pembelian di Mimi Kado Jakarta Utara. Teknik pengumpulan sample menggunakan judgemental sampling, dimana penarikan sampel berdasarkan pertimbangan yang didasarkan kriteria-kriteria tertentu yaitu responden yang telah mengunjungi dan membeli produk Mimi Kado Jakarta Utara sebanyak 130 responden.

C. Operasional Variabel

Operasional variabel menurut Widodo (2018:82) adalah kegiatan pengukuran variabel penelitian dilihat berdasarkan ciri-ciri spesifik yang tercermin dalam dimensi-dimensi atau indikator-indikator variabel penelitian. Variabel yang digunakan dalam penelitian ini adalah sebagai berikut:

\section{a. Operasional Variabel Barang Visual}

Variabel barang visual dalam penelitian ini diukur berdasarkan dimensi-dimensi yang diacu dari penelitian Pancaningrum (2017). Dalam penelitian ini, peneliti mengambil 3 elemen yang paling sesuai dengan karakteristik perusahaan yang ingin dibahas dalam penelitian ini, yaitu:

- Penataan Produk

a. Penataan produk yang unik

b. Kerapihan penempatan produk

- Pewarnaan gerai

a. Pemilihan warna 
b. Kombinasi warna

c. Tampilan warna toko yang menarik

- Keragaman produk

a. Keanekaragaman kategori produk

b. Kebaharuan produk

c. Ketersediaan produk

b. Operasional Variabel Atmosfer Toko

Variabel atmosfer toko dalam penelitian ini diukur teori yang dikemukakan Berman dan Evans yang telah dialih bahasakan oleh Alma (2013:70), Dalam penelitian ini, peneliti mengambil 3 elemen yang paling sesuai dengan karakteristik perusahaan yang ingin dibahas dalam penelitian ini, yaitu:

- Exterior
a. Daya tarik logo
b. Tempat parkir toko
c. Tampilan depan toko

- Store Layout
a. Tampilan dalam toko
b. Penempatan rak toko
c. Jarak antar rak toko

- General Interior
a. Tingkat pencahayaan
b. Aroma yang dihasilkan
c. Suhu dalam ruangan

\section{c. Operasional Variabel Respon Emosional}

Terdapat sebuah model yang dikemukakan oleh Mehrabian-Russel (1974) (Model MR) menyatakan bahwa faktor-faktor lingkungan dan emosi yang berkaitan erat dengan kepribadian individu dapat mempengaruhi respons emosi utama seorang individu, dimana respon emosi tersebut dikenal dengan akronim PAD (Pleasure, Arosal dan Dominance) dan menjadi dimensi untuk variabel respon emosi dalam penelitian ini. Tiap-tiap dimensi memilki 3 indikator yang dibentuk oleh peneliti, indikator-indikator tersebut antara lain:

- Pleasure
a. Rasa nyaman dalam toko
b. Rasa puas
c. Dengan pelayanan yang diberikan 
d. Tertarik dengan tata letak toko

- Arousal
a. Terstimulasi dengan suasana toko
b. Aktif menjelajah toko
c. Aktif mencari produk

- Dominance
a. Tertarik karena keramaian
b. Tertarik karena rekomendasi
c. Dikendalikan lingkungan

\section{d. Operasional Variabel Pembelian Impulsif}

Menurut Utami (2010:67), terdapat 3 perspektif dalam pembelian impulsif menjadi dimensi untuk variabel respon emosi dalam penelitian ini. Dimana dari dimensidimensi tersebut dibentuk masing-masing 3 indikator yaitu antara lain:

- Karakteristik produk baru
a. Daya tarik penampilan
b. Daya tarik harga
c. Stimulasi Visual

- Karakteristik konsumen
a. Motivasi dalam diri
b. Keinginan belanja
c. Takut menyesal

- Karakteristik display tempat belanja
a. Desain rak
b. Kemudahan akses

M. Model Konseptual Penelitian

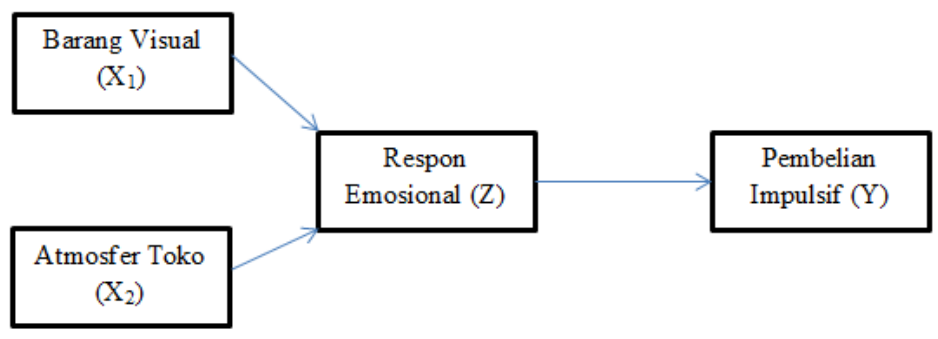

Gambar 3 Model Konseptual Penelitian Sumber : Olahan Peneliti, 2019 


\section{e. Hipotesis Penelitian}

Pengaruh Variabel Visual Merchandising Terhadap Variabel Respon Emosional Pada penelitian yang dilakukan Sudarsono (2017) variabel Barang Visual berhubungan secara signifikan terhadap positive emotion dimana emosi positf ini merupakan bagian dari respon emosional, yang berarti ketika adanya barang visual yang menarik maka akan meningkatkan respon emosional dari pengunjung di tempat tersebut. Selain diacu dari penelitian terdahulu, hipotesis ini juga didukung oleh teori S-O-R (Stimulus-Organism-Respon) yang dikemukakan oleh Skinner pada tahun 1938, dimana penelitian ini, barang visual berperan sebagai stimulus atau pesan yang coba disampaikan, untuk kemudian pesan atau stimulus tersebut diperhatikan, dimengaerti dan di terima oleh publik sebagai konsumen serta direspon dengan perubahan sikap, dalam hal ini sikap afektif berupa respon emosional. Berdasarkan hal tersebut, maka hipotesis pertama dari penelitian ini ialah:

H1 : Barang visual berpengaruh positif dan signifikan terhadap respon emosional

Pengaruh Variabel Atmosfer Toko Terhadap Variabel Respon Emosional Pembentukan hipotesis ini salah satunya didasari oleh penelitian terdahulu, diantaranya yaitu hasil penelitian yang dilakukan oleh Anggoro (2012) dapat diketahui bahwa atmosfer toko berpengaruh terhadap respon emosional, yang berarti ketika adanya atmosfer toko maka akan meningkatkan respon emosional dari pengunjung. Sedangkan penelitian yang dilakukan Madjid (2014) dapat diketahui bahwa atmosfer toko memiliki pengaruh yang positif dan signifikan terhadap emosi kostumer. Selain diacu dari penelitian terdahulu, hipotesis ini juga didukung oleh teori S-O-R (Stimulus-Organism-Respon) yang dikemukakan oleh Skinner (1938), dimana penelitian ini, atmosfer toko berperan sebagai stimulus atau pesan yang coba disampaikan, untuk kemudian pesan atau stimulus tersebut diperhatikan, dimengaerti dan di terima oleh publik sebagai konsumen serta direspon dengan perubahan sikap, dalam hal ini sikap afektif berupa respon emosional. Berdasarkan hal tersebut, maka hipotesis kedua dari penelitian ini ialah: H2 : Atmosfer toko berpengaruh positif dan signifikan terhadap respon emosional

\section{Pengaruh Variabel Respon Emosional Terhadap Variabel Pembelian Impulsif} Pembentukan hipotesis ini salah satunya didasari oleh penelitian terdahulu, diantaranya yaitu hasil penelitian yang dilakukan oleh Salikha (2017) dapat diketahui bahwa respon emosional berpengaruh terhadap pembelian impulsif, yang berarti apabila respon emosional pengunjung meningkat, maka pembelian impulsif akan meningkat. Sedangkan penelitian yang dilakukan oleh Gumilang dan Nurcahya (2016) diketahui bahwa Emotional Shopping memiliki pengaruh secara langsung 
terhadap pembelian impulsif, Berdasarkan hal tersebut, maka hipotesis ketiga dari penelitian ini ialah:

H3 : Respon emosional berpengaruh positif dan signifikan terhadap pembelian impulsif

\section{Hasil dan Pembahasan}

\section{A. Gambaran Umum Penelitian}

Penelitian ini dilakukan untuk mengetahui pengaruh barang visual dan atmosfer toko terhadap respon emosional serta dampaknya pada pembelian impulsif pada Mimi Kado Jakarta Utara.

\section{B. Uji T}

Menurut Priyatno (2009:63), uji statistik T bertujuan untuk menguji apakah hubungan yang terjadi itu berlaku untuk populasi (dapat digeneralisasi).

Berdasarkan hasil olah data uji $\mathrm{T}$ pada sub model pertama dapat dilakukan dengan analisa sebagai berikut:

a. Hasil uji T antara visual merchandising terhadap respon emosional sebesar 2.387 sedangkan nilai t-tabel sebesar 1.978. Sehingga $2.387>1.978$ dan menunjukan bahwa dengan sig. 0,018< $\mathrm{a}=0,05$. Dengan hasil ini maka menerima hipotesis yang menyatakan bahwa visual merchandising berpengaruh positif dan signifikan terhadap respon emosional.

b. Hasil uji $\mathrm{T}$ antara atmosfer toko terhadap respon emosional sebesar 4.699 sedangkan nilai t-tabel sebesar 1.978. Sehingga $4.699>1.978$ dan menunjukan bahwa dengan sig. 0,000 < a =0,05. Dengan hasil ini maka menerima hipotesis yang menyatakan bahwa atmosfer toko berpengaruh positif dan signifikan terhadap respon emosional.

Berdasarkan hasil olah data uji $\mathrm{T}$ pada sub model kedua dapat dilakukan dengan analisa sebagai berikut:

Hasil uji $\mathrm{T}$ antara respon emosional terhadap pembelian impulsif sebesar 5.703 sedangkan nilai t-tabel sebesar 1.978. Sehingga $5.703>1.978$ dan menunjukan bahwa dengan sig. 0,000 < $a=0,05$. Dengan hasil ini maka menerima hipotesis yang menyatakan bahwa respon emosional berpengaruh positif dan signifikan terhadap pembelian impulsif. 


\section{Analisis Regresi Linear Berganda}

Analisis regresi digunakan untuk mengembangkan suatu model hubungan linear antara variabel independen dan variabel dependen. Lalu, untuk memprediksi nilai dari variabel apabila nilai variabel independennya mengalami kenaikan atau penurunan.

Berdasarkan hasil olah data analisis persamaan regresi linear berganda, didapat hasil sebagai berikut:

$Z=9.125+0,255 X 1+0,471 \times 2$

Hasil persamaan yang telah didapatkan, dapat diartikan sebagai berikut:

a. Koefisien regresi barang visual (b1) positif sebesar 0,255 yang dapat diartikan bahwa apabila variabel independen lainnya bernilai tetap dan variabel barang visual mengalami kenaikan sebesar 1 tingkat dapat di simpulkan setiap ada peningkatan barang visual maka akan mempengaruhi peningkatan respon emosional sebesar 0,255.

b. Koefisien regresi atmosfer toko (b2) positif sebesar 0,471 yang dapat diartikan bahwa apabila variabel independen lainnya bernilai tetap dan variabel atmosfer toko mengalami kenaikan sebesar 1 tingkat dapat di simpulkan setiap ada peningkatan atmosfer toko maka akan mempengaruhi peningkatan respon emosional sebesar 0,471 .

Berdasarkan hasil olah data analisis persamaan regresi linear berganda, didapat hasil sebagai berikut:

\section{$Y=16,412+0,421 X 1$}

Hasil persamaan analisis regresi linear berganda tersebut memberi arti sebagai berikut:

Koefisien regresi respon emosional (b1) positif sebesar 0,421 yang dapat diartikan bahwa apabila variabel independen lainnya bernilai tetap dan variabel respon emosional mengalami kenaikan sebesar 1 tingkat dapat di simpulkan setiap ada peningkatan respon emosional maka akan mempengaruhi peningkatan pembelian impulsif sebesar 0,421 .

\section{Conclusion}

\section{A. Simpulan}

Berdasarkan analisis yang telah dilakukan, maka dapat disimpulkan: 1)Barang visual berpengaruh secara postif dan signifikan terhadap respon emosional 
pengunjung Mimi Kado dengan nilai koefisien beta 0.219 dan nilai $t$ hitung (2.387) > t tabel (1.978). 2)Atmosfer toko berpengaruh secara positif dan signifikan terhadap respon emosional pengunjung Mimi Kado dengan nilai koefisien beta 0.431 dan nilai t hitung (4.699) > t tabel (1.978). 3)Respon emosional berpengaruh secara positif dan signifikan terhadap pembelian impulsif pada pengunjung Mimi Kado dengan nilai koefisien beta 0,450 dan nilai $t$ hitung $(5,703)>t$ tabel $(1.978)$

B. Keterbatasan Hasil Penelitian

Dalam penelitian ini memiliki keterbatasan yang disebabkan berbagai faktor, antara lain:

1)Variabel Barang Visual merupakan variabel baru yang digunakan peneliti di Kampus Kalbis Institute sehingga peneliti kesulitan untuk mencari kajian pustaka yang bersangkutan.

2)Objek penelitian yang diambil bukan perusahaan terbuka melainkan UKM dan peneliti mendapatkan izinkan untuk melakukan penelitian di dalam toko ritel tersebut.

3)Peneliti hanya mengambil sampel dengan waktu yang singkat sehingga tidak dapat mewakilkan presepsi secara lebih luas.4)Waktu untuk meminta izin ke perusahaan terbatas dan adanya penolakan di beberapa perusahaan.

C. Implikasi Manajerial

1) Dari sisi Barang visual, untuk dimensi display, Mimi Kado sudah cukup untuk menata produknya dengan baik, akan tetapi perlu ditata dengan unik dan semenarik mungkin agar pengunung tertarik untuk mendatangi produk yang ada dan mampu menarik perhatian pengunjung. Untuk dimensi warna, warna yang ditampilkan baik dari produk sampai toko Mimi Kado sudah cukup dan harus dipertahankan dikarenakan warna pink yang ditampilkan toko tersebut sudah cukup menarik pengunjung. Untuk dimensi keragaman produk, Mimi Kado perlu menambahkan produk baru, produk yang sedang trend di kalangan millenial agar Mimi Kado adalah toko yang dicari ketika mencari cinderamata.

2)Dari sisi atmosfer toko, untuk dimensi exterior yang ditampilkan oleh Mimi Kado dari logo sudah cukup menarik perhatian pengunjung, akan tetapi lahan parkir yang disediakan oleh Mimi Kado harus di tata agar lahan sebesar itu mampu menampung banyak kendaraan, seperti diberikan garis parkir, mengingat toko sebelah pun terkadang parkir di lahan Mimi Kado. Untuk dimensi store layout, mempertahankan apa yang telah diperbuat karena baik tampilan dalam toko, penempatan rak, jarak 
antar rak sudah sesuai. Untuk general interior, tingkat pencahayaan ditambahkan untuk menyorot barang - barang baru sehingga pengunjung dapat mengetahui produk baru toko tersebut, serta aroma dan kesejukan yang dibangun oleh Mimi Kado sudah sangat baik.

3)Dari sisi respon emosional, untuk dimensi pleasure, Mimi Kado perlu membangun suasana yang dapat memberikan perasaan yang nyaman ketika berada di dalam toko. Untuk dimensi arousal, Mimi Kado perlu meningkatkan kemampuan dalam menumbuhkan suasana pengunjung untuk aktif menjelajah ketika berada di Mimi Kado. Dan untuk dimensi Dominance, karyawan Mimi Kado harus aktif untuk menawarkan produk - produk baru ataupun rekomendasi ketika pengunjung datang ke Mimi Kado.

4)Dari sisi pembelian impulsif, untuk dimensi karakteristik produk baru, Mimi Kado perlu meningkatkan daya tarik penampilan dan harga sehingga pengunjung dapat melihat secara jelas produk baru yang ditawarkan. Untuk dimensi karakteristik konsumen, Mimi Kado perlu menawarkan dan aktif memberikan informasi kepada konsumen akan produk yang dimiliki sehingga terjadi pembelian tidak terduga dari konsumen tersebut. Dan untuk dimensi karakteristik display tempat belanja, Mimi

Kado disarankan untuk membuat jalur track toko lebih menarik lagi agar pengunjung dapat aktif menjelajah didalam toko.

\section{Daftar Pustaka}

Buchari, Alma. (2014). Manajemen Pemasaran dan Pemasaran Jasa. Bandung: Alfabeta.

Priyatno, Dwi. (2009). Mandiri Belajar SPSS (Statistical Product and Service Solution) : Untuk Analisis Data dan Uji Statistik. Yogyakarta : MediaKom.

Priyatno, D. (2016). Belajar Alat Analisis Data Dan Cara Pengolahannya Dengan SPSS Praktis dan Mudah Dipahami Untuk Tingkat Pemula dan Menengah. Yogyakarta: Gava Media

Siregar. (2017). Metode Penelitian Kuantitatif: Dilengkapi dengan Perbandingan Perhitungan Manual \& SPSS. Jakarta: Kencana

Sudaryono. (2018). Metodologi Penelitian. Depok: Rajawali Pers

Sunyoto, Danang. (2011). Metode Penelitian Untuk Ekonomi. Yogyakarta: CAPS.

Utami, Christina Whidya. (2010). Manajemen Ritel:Strategi dan Implementaii Operasional Bisnis Ritel Modern Indonesia. Jakarta : Salemba Empat. 
Widodo. (2018). Metodologi Penelitian Populer $\mathcal{E}$ Praktis. Depok: PT Rajagrafindo Persada Katadata.co.id. (2017). Diakses pada tanggal 7 Maret 2019 pukul 10:35 https:/ / databoks.katadata.co.id/ datapublish/2018/04/18/2013-2017 pertumbuhan-penjualan-emiten-ritel-turun.

Finance.detik.com. (2019). diakses pada tanggal 25 Juni 2019 pukul 1:40 https:/ / finance.detik.com/berita-ekonomi-bisnis/d-4390177/ramai-ritel tutup-darmin-dunia-sedang-berubah

Pancaningrum, Erminanti. (2017). "Visual Merchandise dan Atmosfer Toko: Pengaruhnya Terhadap Keputusan Pembelian Impuls".[online].Diakses $\begin{array}{llllll}\text { pada tanggal } & 4 & \text { April } & & \end{array}$ https://www.academia.edu/38280294/V ISUAL_MERCHANDISE_DAN_ATMOSFER_TOKO_PENGARUHNYA_TE HADAP_KEPUTUSAN_PEMBELIAN_IMPULS

Sudarsono, Jovita Guntara. (2017). "Perngaruh Visual Merchandising Terhadap Impulse Buying Melalui Positive Emotion pada Zara Surabaya".[online]. Diakses pada tanggal 4 April 2019 pukul 09:30. https://doi.org/10.9744/pemasaran.11.1.16-25

Anggoro, Sandra Pusoasari. (2012). "Analisis Pengaruh Store Atmosphere Terhadap Impulse Buying Melalui Emotional Response di Matahari Department Store Tunjungan Plaza Surabaya". [online]. Diakses pada tanggal 4 April 2019 pukul 09:27. jurnal.wima.ac.id/index.php/JUMMA/article/view/210

Madjid, R. (2014). “The Influence Store Atmosphere Towards Customer Emotions and Purchase Decisions". [online]. Diakses pada tanggal 4 April 2019 pukul 09:35. http:/ /ijhssi.org/papers/v3(10)/Version-2/B03102011019.pdf

Gumilang, Wayan Aris \& I Ketut Nurcahya. (2006). "Pengaruh Price Discount dan Store Atmosphere Terhadap Emotional Shopping dan Impulse Buying". [online]. Diakses pada tanggal 4 April 2019 pukul 09:28. https:// www.neliti.com/publications/244197/ pengaruh-price-discount-dan store-atmosphere-terhadap-emotional-shopping-dan-imp 